\title{
DESIGN GUIDELINES FOR APPLICATIONS THAT TARgET ARAB DYSLEXIC STUDENTS
}

\author{
Raghad Alsudays \\ Department of Information technology, King Saud University, Riyadh, \\ Kingdom of Saudi Arabia
}

\begin{abstract}
Dyslexia is a specific learning disability that involves difficulties in reading and affects the academic achievement of students with dyslexia, particularly in reading. It is a language-based learning disability, where the severity of difficulties varies across different languages. Arab dyslexic students are in need for tools that support their academic achievement process. The design of most of the educational applications in Arabic language that target dyslexic student, do not meet their special needs and requirements. Our contribution is an analysis of design considerations to reach a suitable design for applications that targets Arab students with dyslexia. The result of our analysis is presented as a number of guidelines that are related to the applications elements.
\end{abstract}

\section{KEYWORDS}

Dyslexic Students, Design Guidelines, Dyslexia, Recommendations, Arabic Language.

\section{INTRODUCTION}

Dyslexia is a specific learning disability that is related originally to neurobiology. It is concerned with difficulties in recognition of fluent words accurately, poor spelling, and decoding abilities [1]. People with dyslexia suffer from a neurological difficulty, hence, their brains process and translate data in an unanticipated manner. This neurological problem also affects their literacy and ability to understand new things [1]. Despite having a developmental disorder of neurobiological origin, dyslexic people have normal or above average intelligence and usually have no sight problems [2]. Students with dyslexia show a difference between their mental abilities and their academic achievement [3]. Thus, they usually have high mental abilities but their academic achievement is low, particularly in reading skills.

Dyslexia can be described as a language-based learning disability, where the severity of reading and writing deficits vary across different languages and cultures [4]. The available research conducted to explore dyslexia in Arabic language mostly focused on the difficulties and complexity of Arabic [5]. These difficulties and complexity of Arabic language could make reading a more difficult skill to be acquired for dyslexic students. Since dyslexia is associated with a language, the linguistic characteristics of the Arabic language should be considered in the design of dyslexia assistive technology in this language [3].

Specialized education program can help dyslexic students to succeed in school [6]. Research has proven that using technology and computer-based training can improve reading abilities of dyslexic students, especially if they were introduced to these technologies at an early age [7]. Unfortunately, the design of most of the applications that target the dyslexic students do not meet their special needs and requirements as they do not follow the general respected guidelines, such 
as the background colours; nor the specific Arabic guidelines, such as using a specific font for Arabic text.

Studies on designing tools to support dyslexics in Arabic language are very limited. Therefore, the aim of this work is to present an analysis of the suitable design aspects required to meet thespecial needs of students with dyslexia. This paper contributes to the HCI field by providing a set of guidelines for designing Arabic learning applications for students with dyslexia.

\section{Design GuIDELINES}

We tried to collect all recommendations related to design Arabic learning applications for students with dyslexia. In order to be considered when designing these applications.

\subsection{Methodology}

We went through the following steps in order to collect all possible recommendations that arerelated to design Arabic learning applications for students with dyslexia.

\subsubsection{Collecting Resources}

First, we collected all possible papers from Saudi Digital Library that mentioned some recommendations to design learning applications for students with dyslexia, which are related to the elements of any application [regardless of the language], using the keywords; Dyslexia, design, guidelines, recommendations. In order to identify the appropriate characteristics of texts for dyslexics, [which involve the font style and size] and how it should be formatted, the suitable colours for dyslexics to be used for texts and backgrounds, as well as the guidelines to be considered when using multimedia. We got a total of 19 papers for analysing the design recommendations.

\subsubsection{Collecting and Analysing Recommendations}

In this step, we collected the recommendations we need from those resources, which are either suggested by dyslexia experts or extracted based on results of questionnaires, workshops, interviews and experiments applied to dyslexics or their parents in addition to specialists in specific learning difficulties. Then, we analyzed these design recommendations to divide them according to the design element [text, colours, formatting, multimedia..etc] and whether they are general and can be applied to applications that target dyslexic students in any language or specific for Arabic language.

\subsubsection{Filtering Results}

Here we filtered the results of the previous step, to abstract only the recommendations related to elements design and agreed upon in those sources.

\subsubsection{Specifying Design Recommendations}

Finally, we identified the design recommendations for dyslexics in guidelines form to be considered while designing applications for dyslexics. 


\subsection{Design Recommendations for Dyslexics}

The findings of our analysis are presented in the form of guidelines that are related to the design elements: font style and size, interface and colors, layout, formatting, navigation, multimedia, repetition and feedback. Some of these design guidelines are general and can be applied to applications that target dyslexic students in any language ; however, the other guidelines are specific for Arabic language applications since that consider the characteristics of Arabic script.

\subsubsection{General Design Guidelines}

Font Style:OpenDyslexic, Lexia Readable, Dyslexie and SylexiadeReadRegular are text fonts that have been developed to maximize the readability of the letters and make them clearer andmore precise for dyslexics [15]. These fonts are presented in figures 1,2 and 3. Dyslexie may not improve the reading speed, but it may decrease some specific type of reading errors [10].

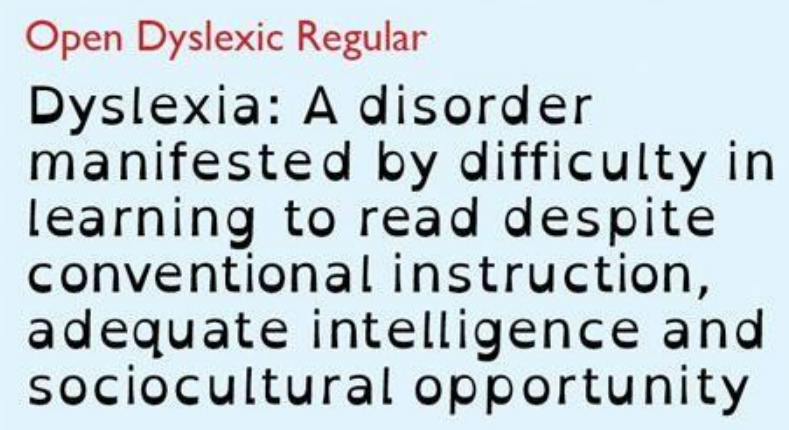

Figure 1. Text written by OpenDyslexic font type

\section{Lexia Readable Bold the quick brown fox jumps over the 1 THE QUICK BROWN FOX JUMPS O 0123456789}

Figure 2. Text written by Lexia Readable font type

\section{The font for people with dyslexia}

This font is especially designed for people with dyslexia. When they use it, they make fewer errors whilst they are reading. It makes reading easier for them and it takes less effort. The Dyslexia font is used by several schools, universities, speech therapists and remedial teachers.

Figure 3. Text written by Dyslexie font type 
Students with dyslexia have difficulties in reading with serif fonts [20], [14]. Therefore, it is better to use 'Sans Serif' since they found it easier to read. The most suitable plain sans serif font types are Arial and Comic Sans MS [21], [22], [23]. Since these font styles do not support Arabic language except Arial, it can be considered as suitable font type for Arabic language as well.

Font Size: Despite the difference in the recommended size; however, larger font size clearly increases text readability [24]. It should be $12-14$ point, or larger to suite the need of some dyslexic readers [15], [14], [23].

Interface and colours: Since some of dyslexics can be visually sensitive to colours, it is recommended to rely on a simple interface design to minimize any disturbance [10], [7], [20]. This design is made using dark coloured text on a light background not the opposite [5], [9],[14]. As background colours can facilitate dyslexics to read better; red, white and graphics backgrounds have to be avoided since they make text harder to read [15], [22]. Dyslexia experts have listed eight suggested background colour that are illustrated in figure 4 [colour code: \#FF3E2, \#A4D5A6,\#CCE685, \#A8E685, \#DED8E4,\#87AA74, \#9E9E7C, \#F19D3B] [20],[14]. Additionally, it is recommended to avoid green and red/pink coloured text [15].

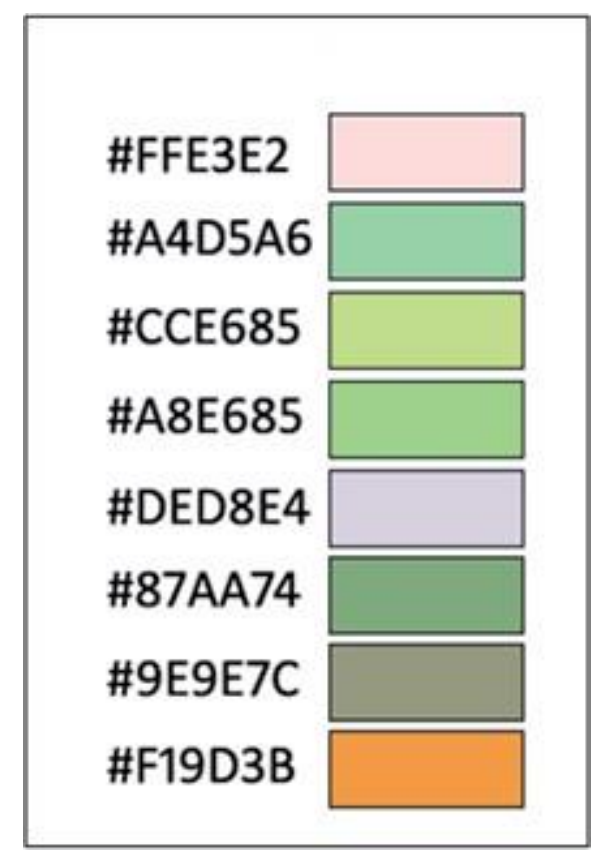

Figure 4. backgroundcolours proposed by an expert

We concluded with the following combinations of text and background colours as they are proven to be preferable by dyslexics:

- Black text on a beige or cream background [9], [23].

- Black text on yellow background [9].

- Black text on lighter shades of pink and green background [21].

Moreover, dyslexic students get confused with too many colours and options in the screen. Therefore, the menu and its options in general should have few basics colours to prevent confusion [3]. 
However, since dyslexics have different preferences, various research studies demonstrate that enabling dyslexic users to customize text and background colours as well as font types and sizes according to their preferences has a significant influence on their reading accuracy [10], [20], [15], [14].

Layout: Lines should not be too long: 60 to 70 characters. Narrow columns should be avoided in addition to starting a sentence at the end of a line [9], [14], [15].

Formatting: It is recommended to use bold or coloured text for important texts rather than italic or underline [15], [25]. It is also recommended to use larger font size in bold for headings [14] and at least 1.5 line spaces between lines of text [15].

Navigation: Dyslexics show difficulty in navigation. Therefore, Simple and clear navigation design is recommended to overcome the problem of weak focus on coherence [20], [3], [14]. Simple navigation includes simple menus that present few options to choose from and categorize the relevant options in new submenu [3], [21]. Moreover, experts recommendedadding Home button and Back button on every page to facilitate the return to the home page or to the previous page [16]. Additionally, program closing, which is part of navigation, is suggested to be presented in a clear red closing icon to allow users to perceive its function [3].

Multimedia: Using relevant multimedia elements is an effective approach of teaching students with dyslexia [1]. It includes adding useful pictures, tables, graphics, audios and videos to help in attracting the attention and improve understanding the content [15], [21], [25], [14]. Nonetheless, sound effects and visual design may distract dyslexic students from the main educational purpose [10]. Therefore, it is recommended to avoid using animated text, unnecessary images and text in images [21], [14]. It is good to provide narrator voice with any texts [14], that needs to be presented slowly to assist dyslexic students in understanding and allow for audio information processing [22], [20]. The voice also needs to be cheerful to maintain their interests and focus. In addition, it is encouraged to use music as background during learning [22]. Furthermore, it is essential to add label to the videos that indicate their duration and make them able to play in full screen in order to enhance the system status visibility [16].

Repetition: Repetition of words helps students with learning difficulties to read [1]. It includes providing the opportunity to repeat the same activity [14] or offering a number of attempts until mastery of the task is completed [5].

Feedback: Providing appreciative audio feedback helps in attracting the attention of dyslexic students [21], [14]. For assessment of reading skills and easy feedback, it is recommended to allow user to select the word pronounced by the system among different words. If the user selected the correct word, this means he/she read it correctly [3].

\subsubsection{Arabic Language Specific Design Guidelines}

Font style: Times New Roman font Arabic text in large print is recommended to enhance reading performance [10]. The preferred Arabic text font are Arabic Transparent followed by Simplified Arabic Fixed. On the other hand, angular types of Arabic fonts such as Koufi and Andalus should be avoided [25].

Font size: Since Arabic script is commonly written in larger sizes than English, the preferred size is in the 16-20pt range [25]. 
Formatting: Due to the nature of Arabic script, alignment of text should be from right to left. Fully justified text is suitable for Arabic dyslexics as well, because words can be stretched to fill the width of the line instead of introducing inconsistent spaces between words. Moreover, it is recommended to increase spacing between words [25].

Vowelization: Since reading words is an advance step after learning letters, using of diacritics [the markings that may appear above and below letters to define their pronunciation] could improve comprehension and reading accuracy, especially for beginner readers [3], [25]. However, reading with diacritics may reduce the reading comfort for both beginners and experienced readers as it requires high levels of visual discrimination and memory skills. Therefore, it is suggested to provide text in both formats and give users the option to hide or view the short vowels as well as offering levels of vowelization [25].

These guidelines are summarized in table 1 .

Table 1: Summary of design recommendations for dyslexics

\begin{tabular}{|c|c|c|}
\hline & Design element & The recommendations \\
\hline \multirow{9}{*}{$\begin{array}{c}\text { General } \\
\text { design } \\
\text { guideline }\end{array}$} & Font Style & $\begin{array}{l}\text { - Fonts specially designed for dyslexic: OpenDyslexic, Lexia } \\
\text { Readable, Dyslexie and SylexiadeReadRegular. } \\
\text { - Use 'Sans Serif' font types: Arial and Comic Sans MS. }\end{array}$ \\
\hline & Font Size & 12-14 point, or larger. \\
\hline & $\begin{array}{l}\text { Interface and } \\
\text { colors }\end{array}$ & $\begin{array}{l}\text { - Text color: black. } \\
\text { - Background color: beige, yellow, lighter shades of pink and green }\end{array}$ \\
\hline & Layout & $\begin{array}{l}\text { - } \quad 60 \text { to70 characters for each line. } \\
\text { - } \quad \text { Avoid Narrow columns. } \\
\text { - Avoid starting a sentence at the end of a line. }\end{array}$ \\
\hline & Formatting & $\begin{array}{l}\text { - Use bold or colored text for important piece. } \\
\text { - Use larger font size in bold for headings. } \\
\text { - Leave } 1.5 \text { line spaces at least between lines of text. }\end{array}$ \\
\hline & Navigation & $\begin{array}{l}\text { - Use simple menus that present few options to choose from. } \\
\text { - Add Home button and Back button in every page. } \\
\text { - Present a clear red closing icon for program closing. }\end{array}$ \\
\hline & Multimedia & $\begin{array}{l}\text { - Add images, audios and videos to improve understanding the } \\
\text { content. } \\
\text { - Use music as background during learning. } \\
\text { - Avoid using animated text, unnecessary images and text in } \\
\text { images. } \\
\text { - Provide narrator voice that ischeerful and presented slowly } \\
\text { with any text. }\end{array}$ \\
\hline & Repetition & Allow repeating words and activities. \\
\hline & Feedback & Provide appreciative audio feedback toattract the attention. \\
\hline \multirow{4}{*}{$\begin{array}{c}\text { Arabic } \\
\text { language } \\
\text { specific } \\
\text { design } \\
\text { guidelines }\end{array}$} & Font style & $\begin{array}{l}\text { - Use Arabic font types: Times New Roman, Arabic Transparent } \\
\text { and Simplified Arabic Fixed. } \\
\text { - Avoid angular types of Arabic fonts: Koufi and Andalus. }\end{array}$ \\
\hline & Font size & Size is in the 16-20pt range. \\
\hline & Formatting & $\begin{array}{ll}\text { - } & \text { Text alignment should be from right to left. } \\
\text { - } & \text { Fully justified text. } \\
\text { - } & \text { Increase spacing between words. }\end{array}$ \\
\hline & Vowelization & Use \\
\hline
\end{tabular}




\section{RElated ARABIC WORKS}

Studies on designing and developing tools to support dyslexics in Arabic are very limited. Despite the lack of works conducted in this field, there are number of research and investigations have been made to help dyslexic students with Arabic language.

Al-dabaybah and Jusoh designed a methodology to identify the usability features for developing an Arabic assistive technology for dyslexic students [3]. They adopted a set of tasks or questions to be used in the experiments. The features were extracted by conducting experiments on three dyslexics and three normal students age between seven to ten years old to match the target users need. Four applications designed for children literacy teaching were used as tools for experiments. They asked the students to perform a list of tasks, and then observed their ability to perform the given tasks. The results suggested a set of required usability features that are related to the use of menus, colours, navigation and feedback. Some of these features were discussed in the previous section to be considered as recommendations for designing applications for dyslexics.

Moreover, [8] developed a novel, interactive, multimodal interfaced mobile learning tool based on a cloud-computing architecture. Using this tool enables dyslexic students to learn educational materials, carry out exercises and interact with the content based on their profile and preferred learning style. The tool aims to enhance the learning capabilities of students with dyslexia. It consists of lessons in Arabic language classified into letter-reading lessons and word-reading lessons. Each lesson has related exercises where the content is presented using audio and visual components, such as images and texts. Figure 5 shows different screenshots of the mobile learning tool. They designed a questionnaire to evaluate the students' level of satisfaction with the tool. The result shows that it improves the learning skills levels to the double compared to the traditional learning system. This tool has a rather confusing interface design with too many colours and images in one screen. 
International Journal of Education (IJE) Vol.9, No.2, June 2021
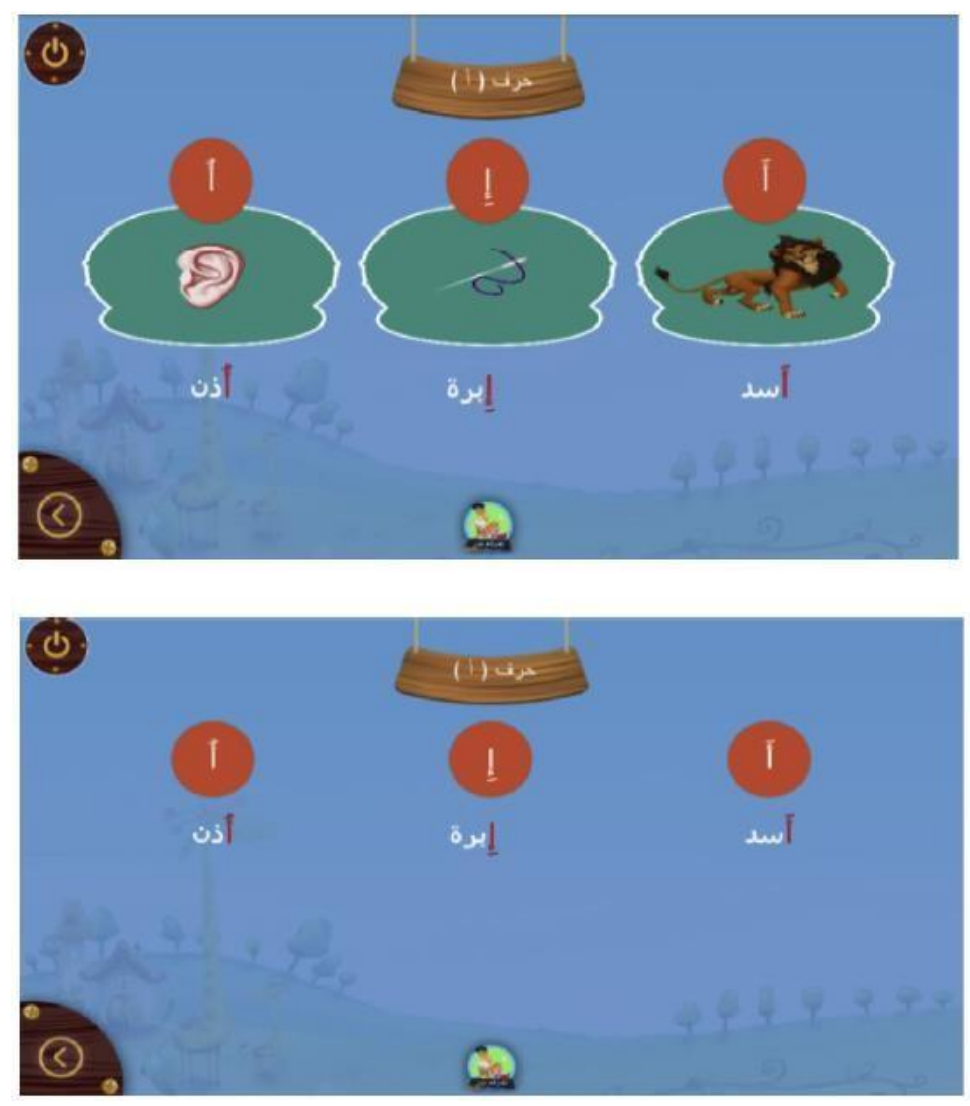

Figure 5. Screenshots of the mobile learning tool

Furthermore, another study presented games for dyslexic students that target Arabic learning disabilities and help students of less than nine years old with dyslexia and learning disabilities [10]. The proposed games are created using Construct 2 HTML5-based engine, which supports most major platforms. They included letters game where the player identifies the Arabic letters and their pronunciations, words game where the player constructs words, as well as sentences game that tests the ability to create meaningful sentences. The games contain written representation, sounds and images to activate both the auditory and visual memories, in order to assist dyslexic students in overcoming the complications of reading and writing that appear as a lack of short and visual memory. Figure 6 shows different screenshots of the games. The games were evaluated and tested by 46 dyslexic students and students with general learning disabilities age from seven to nine years old. The results proved statistically the efficiency of the system and its role in improving the learning process of both dyslexic and normal students. However, we think that the interfaces design was somehow confusing and not appropriate for dyslexic students' needs as it included too many colours, images and options. 


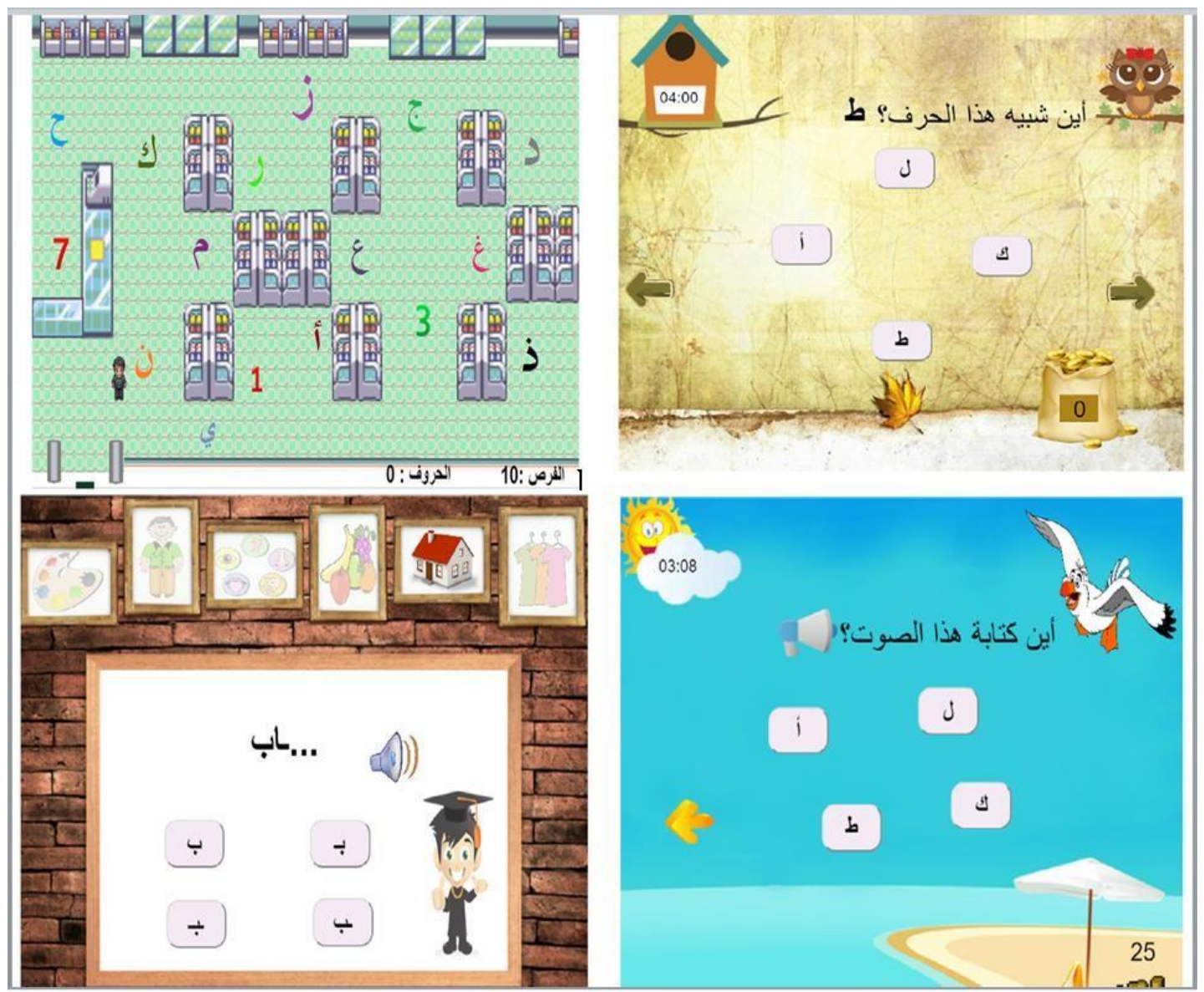

Figure 6. Screenshots of the games

It is noticed that all of those presented applications have confusing interface design that may distract students with dyslexia. Which shows the need for applications design guidelines for dyslexics.

\section{Conclusions}

Reading could be a difficult process for dyslexic students, who suffer from a learning disability that affects their literacy skills. Dyslexia is one of the most common learning disabilities related originally to neurobiology and causes reading problems. It has become an international concern since it affects a large population all over the world. The deficits of reading and the time required for learning of reading vary across different languages, where dyslexia can be described as a language-based learning disability. This project contributes to the field of HCI by providing an analysis of design considerations meet the special needs of dyslexic students. We presented them in the form of guidelines that can be used for designing learning applications that target students with dyslexia.

\section{ACKNOWLEDGEMENTS}

I would like to thank my supervisors, Dr.BalsamAlsugair from Information Technology Department of KSU and Dr.MahaAlsheaha from the Special Education Department of KSU, for their unwavering support and expert advice. 


\section{REFERENCES}

[1] N. Aljojo, A. Munshi, W. Almukadi, A. Hossain, N. Omar, B. Aqel, S. Almhuemli, F. Asirri, and A. Alshamasi, "Arabic Alphabetic Puzzle Game Using Eye Tracking and Chatbot for Dyslexia,’'International Journal of Interactive Mobile Technologies [iJIM], vol. 12, no. 5, p. 58, 2018

[2] Gizem, Aksahya\&Ayese, OzcanCoomunications\& Networks, Network Books, ABC Publishers. 2009.

[3] B. Aldabaybah and S. Jusoh, "Usability Features for Arabic Assistive Technology for Dyslexia," 2018 9th IEEE Control and System Graduate Research Colloquium [ICSGRC], 2018.

[4] Elbeheri, Gad \&Everatt, John \& Reid, Gavin \&Mannai, Haya.. Dyslexia assessment in Arabic. Journal of Research in Special Educational Needs. 6. 143 - 152. 10.1111/j.1471- 3802.2006.00072.x, 2006.

[5] Rowais, Fadwa\& Wald, Mike \& Wills, Gary.. An Arabic framework for dyslexia training tools, 2013.

[6] Procedural Guide for Special Education (in Arabic). kingabdullah bin abdulaziz public education development project. First Edition, 2015.

[7] Al-Ghurair, N. \&Alnaqi, G... Adaptive Arabic application for enhancing short-term memory of dyslexic children. Journal of Engineering Research 7, 2019.

[8] W. G. Alghabban, R. M. Salama, and A. H. Altalhi, "Mobile cloud computing: An effectivemultimodal interface tool for students with dyslexia," Computers in Human Behavior, vol. 75, pp. 160-166, 2017.

[9] F. E. Benmarrakchi, J. El Kafi, A. Elhore, and S. Haie, "Exploring the use of the ICT in supporting dyslexic students' preferred learning styles : A preliminary evaluation," Education and Information Technologies, vol. 22, no. 6, pp. 2939-2957, 2016.

[10] A. El Kah and A. Lakhouaja, "Developing effective educative games for Arabic children primarily dyslexics," Education and Information Technologies, vol. 23, no. 6, pp. 2911-2930, 2018.

[11] A. Y. Alsobhi, N. Khan, and H. Rahanu, "Toward Linking Dyslexia Types and Symptoms to the Available Assistive Technologies," 2014 IEEE 14th International Conference on Advanced Learning Technologies, 2014.

[12] Friedmann, Naama\& Haddad-Hanna, Manar.. Types of Developmental Dyslexia in Arabic, 2014.

[13] R. Béland and Z. Mimouni, "Deep dyslexia in the two languages of an Arabic/French bilingual patient," Cognition, vol. 82, no. 2, pp. 77-126, 2001.

[14] Aziz, FakhrulAnuar and Husni, Husniza [2012] Interaction design for dyslexic children reading application: A guideline. In: Knowledge Management International Conference [KMICe] 2012, $4-6$ July 2012, Johor Bahru, Malaysia.

[15] J. Madeira, C. Silva, L. Marcelino, and P. Ferreira, "Assistive Mobile Applications for Dyslexia,"Procedia Computer Science, vol. 64, pp. 417-424, 2015.

[16] A. Osman, W. A. Yahaya, and A. C. Ahmad, "Educational Multimedia App for Dyslexia Literacy Intervention: A Preliminary Evaluation," Procedia - Social and Behavioral Sciences, vol. 176, pp. 405-411, 2015.

[17] Elbeheri, G., Everatt, J., Mahfoudhi, A., \& Abu Al-Diyar, M.. Dyslexia: A Guide for Arab Researchers [in Arabic]. Kuwait: CCET, 2009.

[18] Al-Abdullatif, S. A guide in learning difficulties The General Administration of Public Education in Riyadh. 2016.

[19] Teachers Guide: Learning Difficulties. Ministry of Education. The Public Administration for Special Education. Management of Learning Difficulties, 2015.

[20] H. Husni, Z. Jamaludin, and F. A. Aziz, "DYSLEXIC CHILDREN'S READING APPLICATION: DESIGN FOR AFFECTION," Journal of Information and Communication Technology, 2013.

[21] Tariq, Rabbia\& Latif, Seemab. A Mobile Application to Improve Learning Performance of Dyslexic Children with Writing Difficulties. Educational Technology \& Society. 19. 151-166, 2016.

[22] Rahim, S. K. N. A., Nasrudin, N. H., Azmi, A. Z., Junid, R. A., Mohamed, Z., \& Abdullah, I. I. B.. Designing Mobile Application for Dyslexia in Reading Disorder Problem. International Journal of Academic Research in Business and Social Sciences, 8[1], 628-646, 2018.

[23] K. Kous and G. Polančič, "Empirical Insights of Individual Website Adjustments for People with Dyslexia," Sensors, vol. 19, no. 10, p. 2235, 2019.

[24] Chen, Chwen Jen \&Keong, Melissa \&Teh, Chee Siong\&Chuah, Kee-Man. Learners with Dyslexia: Exploring their experiences with different online reading affordances. Themes in Science \& Technology Education. 8. 63-79, 2015. 
International Journal of Education (IJE) Vol.9, No.2, June 2021

[25] A. Al-Wabil, P. Zaphiris, and S. Wilson, "Web Design for Dyslexics: Accessibility of Arabic Content," Lecture Notes in Computer Science, pp. 817-822, 2006.

[26] R. Canteri, L. García, T. Felipe, L. Galvão, and D. Antunes, "Conceptual Framework to Support a Web Authoring Tool of Educational Games for Deaf Children," Proceedings of the 11th International Conference on Computer Supported Education, 2019.

[27] K. Porayska-Pomsta, K. Anderson, S. Bernardini, K. Guldberg, T. Smith, L. Kossivaki, S. Hodgins, and I. Lowe, "Building an Intelligent, Authorable Serious Game for Autistic Children and Their Carers," Lecture Notes in Computer Science, pp. 456-475, 2013.

[28] B. A. AlGhannam, S. A. Albustan, A. A. Al-Hassan, and L. A. Albustan, "Towards a StandardArabic System Usability Scale: Psychometric Evaluation using Communication Disorder App,'International Journal of Human-Computer Interaction, vol. 34, no. 9, pp. 799-804, 2017.

\section{AUTHOR}

Raghad Alsudays, master student from Information Technology Department of KSU. 